\title{
Cysteine Protease-Dependent Mucous Disruptions and Differential Mucin Gene Expression in Giardia duodenalis Infection
}

\author{
Christina B. Amat, ${ }^{*}$ Jean-Paul Motta, ${ }^{*}$ Elena Fekete, ${ }^{*}$ France Moreau,${ }^{\dagger}$ Kris Chadee $^{\dagger}{ }^{\dagger}$ and Andre G. Buret*
}

From the Department of Biological Sciences, * University of Calgary, Calgary, Alberta; and the Department of Microbiology, Immunology and Infectious Diseases, ${ }^{\dagger}$ Cumming School of Medicine, Calgary, Alberta, Canada

Accepted for publication July 6, 2017.

Address correspondence to Andre G. Buret, Ph.D., Department of Biological Sciences, Faculty of Sciences, University of Calgary, 2500 University Dr. N.W., Calgary, Alberta T2N 1N4, Canada; or Kris Chadee, Ph.D., Department of Microbiology, Immunology and Infectious

Diseases, Cumming School of Medicine, 3330 Hospital Dr. N.W., Calgary, Alberta T2N 4N1, Canada. E-mail: aburet@ucalgary.ca or kchadee@ucalgary.ca.

\begin{abstract}
The intestinal mucous layer provides a critical host defense against pathogen exposure and epithelial injury, yet little is known about how enteropathogens may circumvent this physiologic barrier. Giardia duodenalis is a small intestinal parasite responsible for diarrheal disease and chronic postinfectious illness. This study reveals a complex interaction at the surface of epithelial cells, between $G$. duodenalis and the intestinal mucous layer. Here, we reveal mechanisms whereby $G$. duodenalis evades and disrupts the first line of host defense by degrading human mucin-2 (MUC2), depleting mucin stores and inducing differential gene expression in the mouse small and large intestines. Human colonic biopsy specimens exposed to $G$. duodenalis were depleted of mucus, and in vivo mice infected with $G$. duodenalis had a thinner mucous layer and demonstrated differential Muc2 and Muc5ac mucin gene expression. Infection in $\mathrm{MuC2}^{-/-}$mice elevated trophozoite colonization in the small intestine and impaired weight gain. In vitro, human LS174T goblet-like cells were depleted of mucus and had elevated levels of MUC2 mRNA expression after $G$. duodenalis exposure. Importantly, the cysteine protease inhibitor E64 prevented mucous degradation, mucin depletion, and the increase in MUC2 expression. This article describes a novel role for Giardia's cysteine proteases in pathogenesis and how Giardia's disruptions of the mucous barrier facilitate bacterial translocation that may contribute to the onset and propagation of disease. (Am J Pathol 2017, 187: 2486-2498; http://dx.doi.org/10.1016/j.ajpath.2017.07.009)
\end{abstract}

Giardia duodenalis (Giardia lamblia, Giardia intestinalis), the causative agent of giardiasis, is a protozoan parasite that infects animals and humans across the globe. Annually, it infects hundreds of millions of individuals worldwide, which led to its inclusion in the World Health Organization's Neglected Disease Initiative. ${ }^{1}$ Moreover, giardiasis is a detriment to the agricultural economy because it causes weight loss in animals. ${ }^{2,3}$ In humans, the pathogenic effects of $G$. duodenalis result in severe malnutrition and malabsorptive diarrhea and, in some cases, especially in young children and in those in developing countries, impaired weight gain and an ultimate failure to thrive. ${ }^{4,5}$ Moreover, giardiasis has been implicated in long-term and extraintestinal consequences, including arthritis, skin allergies, myopathy, and diminished cognitive function. ${ }^{4}$ Recent evidence has revealed that acute $G$. duodenalis infection may lead to chronic functional gastrointestinal disorders, including postinfectious irritable bowel syndrome (IBS). ${ }^{6}$ Indeed, follow-up studies of a 2004 waterborne outbreak of giardiasis in Norway indicated that up to $80 \%$ of patients who experienced giardiasis developed IBS-like symptoms after the clearance of the parasite. ${ }^{6,7}$ The mechanisms that underlie the transition of an acute, transient infection into

\footnotetext{
Supported by Natural Sciences and Engineering Research Council of Canada discovery grant 183681-2011 and Collaborative Research and Training Experience (CREATE) grant 413888-2012 (A.G.B. and K.C.); Crohn's and Colitis Canada-Grant in Aid of Research 20142017 (A.G.B.); a graduate student scholarship from the Alberta Scholarship programs, a Natural Sciences and Engineering Research Council of Canada CREATE graduate scholarship, and a graduate scholarship from the Canadian Association of Gastroenterology (C.B.A.); and an Alberta Health Innovation Solutions postdoctoral fellowship and an Eyes High postdoctoral fellowship from the University of Calgary (J.-P.M.).

Disclosures: None declared.
} 
chronic IBS symptoms remain unknown. Currently, no prophylaxis is available against giardiasis, but an established infection in humans is often treated with nitroimidazole drugs, including the common antiparasitic, metronidazole. ${ }^{8}$ Unfortunately, increasing rates of resistance have been documented in the literature, underlining the need for novel therapeutic discovery. ${ }^{9,10}$

On ingestion, infectious $G$. duodenalis cysts undergo excystation in the small intestine to release the diseasecausing trophozoites, which further divide and proliferate. Before attaching to epithelial cells via a ventral adhesive disk, trophozoites must penetrate the mucous layer, which is designed to protect against invading pathogens. The small intestinal mucous layer is irregular and loosely attached, whereas the colon is lined by a continuous, double mucous layer-an inner sterile layer firmly attached to the epithelium and a loose, porous layer that contains resident bacteria. ${ }^{11}$ Goblet cells in the epithelium secrete mucins, of which 20 have been identified. Mucin-2 (MUC2), mucin5AC (MUC5AC), mucin-5B (MUC5B), mucin-6 (MUC6), and mucin-19 (MUC19) are the oligomerizing secreted mucins. Human MUC5AC (mouse Muc5ac) is typically only found in the respiratory tract and stomach, whereas MUC2 (mouse Muc2) is the main component of mucus in the small and large intestines. ${ }^{12}$ After oligomerization and glycosylation, mature mucins are packaged into secretory vesicles and stored in the apical cytoplasm of goblet cells. ${ }^{13,14}$ Mucins are released constitutively via vesicle membrane fusion and released via exocytosis in response to external stimuli. ${ }^{13,14}$ Once released, mucins expand in the luminal water to form a viscous protective barrier. Despite its critical importance to mucosal homeostasis, the regulation of mucin production and secretion in health and disease remains incompletely understood.

The interactions between $G$. duodenalis and the intestinal mucous barrier remain obscure. Although isolated reports have described that some parasites may damage the mucous layer via secreted proteases, ${ }^{15,16}$ the role of Giardia's cysteine proteases, of which 27 with uncharacterized functions are found in the genome, ${ }^{17}$ remains unclear. The results of this study describe how Giardia, via its cysteine proteases, degrades the intestinal mucous layer and depletes goblet cell mucins to impair mucous barrier function. Our findings also describe differential mucin gene expression in response to intestinal infection.

\section{Materials and Methods}

\section{Statement of Ethics}

Experiments involving animals were approved by the University of Calgary's Animal Care Committee that adheres to the governance of the Canadian Council on Animal Care (certificate AC13-0067). Studies involving human biopsy tissues were approved by the Conjoint Health Research Ethics Board at the University of Calgary and the Calgary
Health Region (certificate REB14-2430 REN1). In accordance with Conjoint Health Research Ethics Board guidelines, subjects used in this study provided informed written or guardian-overseen consent.

\section{Reagents}

The irreversible broad-spectrum cysteine protease inhibitor trans-epoxysuccinyl-L-leucylamido(4-guanidino)butane (E64) was purchased from Sigma-Aldrich (Oakville, Ontario, Canada). The membrane-permeant, cathepsin B-specific inhibitor [2S,3S-3-propylcarbamoyloxirane-2carbonyl]-L-isoleucyl-L-proline methyl ester (Ca074Me) was purchased from Peptide Institute, Inc. (Osaka, Japan). The selectivity of this inhibitor was recently validated. ${ }^{18,19}$ The selective phosphatidylinositol 3-kinase (PI3K) inhibitor 2-(4-morpholinyl)-8-phenyl-4H-1-benzopyran-4-one (LY294002) and the highly-selective cell-permeable protein kinase $\mathrm{C}$ (PKC) inhibitor 3-[1-[3-(dimethylamino)propyl]-1H-indol-3-yl]-4-(1H-indol-3-yl)-1H-pyrrole-2,5-dione [bisindolylmaleimide I (BIM1)] were purchased from Cayman Chemical (Ann Arbor, MI). The function-blocking antibody specific for $\alpha_{v} \beta_{3}$ integrin LM609 was purchased from EMD Millipore (Etobicoke, Ontario, Canada). 7-Hydroxy-3-(4-methoxyphenyl)-4H-1-benzopyran-4-one, 7-hydroxy-3-(4-methoxyphenyl)chromone, and 7-hydroxy$4^{\prime}$-methoxyisoflavone (formononetin) ${ }^{20}$ used to detach $G$. duodenalis trophozoites from cells were purchased from Sigma-Aldrich.

\section{G. duodenalis Culture}

G. duodenalis NF (Assemblage A) was originally isolated from contaminated water that caused a human epidemic of giardiasis in Newfoundland, Canada. G. duodenalis GS/M isolate (Assemblage B) was purchased from ATCC (Manassas, VA). Trophozoites were cultured axenically in polystyrene conical tubes with Keister's modified TY1-S-33 medium $^{21}$ supplemented with penicillin-streptomycin (Sigma-Aldrich) and used at culture peak density.

\section{Human Biopsies}

Mucosal biopsy specimens from the descending colon of 5 healthy human donors were collected during routine screening for colon cancer (Intestinal Inflammation Tissue Bank, University of Calgary, Calgary, Alberta, Canada). On collection, samples were washed to remove loosely adherent mucus and bacteria, then incubated with $1.0 \times 10^{7} / \mathrm{mL} \mathrm{NF}$ $G$. duodenalis trophozoites for 3 hours in prewarmed Hanks' balanced salt solution, as described previously. ${ }^{22}$

\section{Human Colonic Epithelial Cells}

The human colonic epithelial cell line LS174T (ATCC CL188) was grown in minimum essential medium Eagle 
solution (M7278; Sigma-Aldrich) supplemented with $100 \mu \mathrm{g} / \mathrm{mL}$ of streptomycin, $100 \mathrm{U} / \mathrm{mL}$ of penicillin, 200 $\mathrm{mmol} / \mathrm{L}$ of L-glutamine, $5 \mathrm{mmol} / \mathrm{L}$ of sodium pyruvate (all purchased from Sigma-Aldrich), and 10\% heat-inactivated fetal bovine serum (Thermo Fisher Scientific, Ottawa, Ontario, Canada). Cells were passaged at $80 \%$ confluence via detachment with $2 \times$ trypsin-EDTA and seeded onto 6 well plates (VWR, Mississauga, Ontario, Canada) for realtime quantitative PCR (qPCR) or 8-well chamber slides (Thermo Fisher Scientific) for staining. Cells were maintained at $37^{\circ} \mathrm{C}, 5 \% \mathrm{CO}_{2}$, and $96 \%$ humidity and media replaced every 2 to 3 days. Cells on chamber slides were incubated with $G$. duodenalis NF or GS/M trophozoites at a multiplicity of infection of 20 trophozoites per cell (20:1), for various time points. G. duodenalis NF trophozoites were used in all in vitro studies with LS174T cells, unless otherwise stated. After incubation with $G$. duodenalis, cells were washed and exposed to formononetin in cell media to remove adherent trophozoites. ${ }^{20}$ Cells were fixed in $4 \%$ paraformaldehyde (Santa Cruz, Mississauga, Ontario, Canada), stained with fluorescein-coupled wheat germ agglutinin (WGA) (Thermo Fisher Scientific), and mounted with DAPI (Sigma-Aldrich). Images were acquired using a Leica DMR Microscope (epifluorescence) and Leica DM IRE2 (confocal). A ratio of WGA-positive surface area to DAPIpositive surface area was performed on ImageJ software version 1.51 (NIH, Bethesda, MD; http://imagej.nih.gov/ij). For inhibition studies, cells were pretreated for 30 minutes with $20 \mu \mathrm{mol} / \mathrm{L}$ PI3K inhibitor LY294002, $10 \mu \mathrm{mol} / \mathrm{L}$ PKC inhibitor BIM1, or $5 \mu \mathrm{g} / \mathrm{mL}$ antiintegrin $\alpha_{\mathrm{v}} \beta_{3}$ antibody LM609 for 5 minutes before incubation with G. duodenalis trophozoites.

\section{Animal Studies}

Male and female $\mathrm{Muc2}^{-1-}$ mice of C57BL/6 genetic origin, aged 5 to 9 weeks, originally sourced from Velcich et al, ${ }^{23}$ were bred in-house as described in Cobo et al. ${ }^{24}$ Male and female C57BL/6 mice, aged 5 to 9 weeks were ordered from Charles River Laboratories (St-Constant, Quebec, Canada). Mice were orally gavaged with $1.0 \times 10^{7} \mathrm{GS} / \mathrm{M} \mathrm{G}$. duodenalis trophozoites in $0.1 \mathrm{~mL}$ of $70 \%$ TY1-S-33, 30\% $\mathrm{NaHCO}_{3}$ medium or with $0.1 \mathrm{~mL}$ of $70 \%$ TY1-S-33, 30\% $\mathrm{NaHCO}_{3}$ medium as the vehicle control. Mice were weighed daily and euthanized by cervical dislocation. Trophozoite counts were performed by excising $3-\mathrm{cm}$ sections from the jejunum and colon of euthanized mice. The sections were cut longitudinally, placed in tubes with $1 \mathrm{~mL}$ of phosphate-buffered saline (PBS; Sigma-Aldrich), and placed on ice for 15 minutes to aid in trophozoite detachment from the tissue. Before counting, the tubes were thoroughly vortexed to detach remaining trophozoites, and $10 \mu \mathrm{L}$ of solution was pipetted into a hemocytometer for counting with a light microscope. For bacterial translocation assays, mouse liver and spleen were collected aseptically, weighed, homogenized, and plated on 5\% Columbia blood agar plates (VWR). Samples were incubated aerobically and anaerobically for 48 hours. Bacterial colony-forming units were enumerated and normalized to grams of tissue. For cytokine assays, mouse jejunal tissue was homogenized in 1 $\mathrm{mL}$ of lysis buffer $[20 \mathrm{mmol} / \mathrm{L}$ Tris- $\mathrm{HCl}, 150 \mathrm{mmol} / \mathrm{L} \mathrm{NaCl}$, $0.5 \%$ Tween-20, and a Complete Minitab protease inhibitor cocktail (Sigma-Aldrich)]. Cytokine expression levels were assessed via a Luminex Discovery Assay (Eve Technologies, Calgary, Alberta, Canada) according to the manufacturer's protocol.

\section{Fluorescent Staining of Mouse Intestinal Tissue and Histologic Analysis of Human Biopsies}

Sections $1 \mathrm{~cm}$ thick of proximal jejunum and proximal colon were fixed in Carnoy's fixative (60\% ethanol-100\%, $30 \%$ chloroform, $10 \%$ glacial acetic acid) or $4 \%$ paraformaldehyde. Visualization of intestinal microbiota was performed using fluorescent in situ hybridization (FISH) according to a previously published protocol. ${ }^{25}$ The mucous layer was stained in these sections using fluorescein-WGA to stain sialic acid and $\mathrm{N}$-acetylglucosamine residues, and slides were mounted with DAPI. Quantifications of mucous layer thickness and WGA-positive staining were determined using ImageJ software. Human biopsy specimens were fixed in $4 \%$ paraformaldehyde, and mucin content was stained using periodic acid-Schiff/Alcian blue (PAS/AB) as per manufacturer instructions (Newcomer Supply, Middleton, WI). Mucin surface area was quantified using ImageJ software.

\section{Western Blot Analysis for Mucous Degradation}

Secreted mucin was purified from LS174T human gobletlike cells as previously described. ${ }^{26}$ In brief, supernatant collected from LS174T cells was dialyzed, lyophilized, and resuspended in Tris- $\mathrm{HCl}$ buffer that contained sodium azide, followed by fractionation on a Sepharose 4B gel filtration column. High-molecular-weight mucin fractions in the void volume were dialyzed again and concentrated using centrifugal filter units. G. duodenalis NF trophozoites secreted product was obtained from centrifugation of trophozoites incubated in PBS for 2 hours and concentrated using 3-kDa centrifugal filter units (EMD Millipore). Secreted products were incubated with or without $20 \mu \mathrm{g} / \mathrm{mL}$ of E64 for 30 minutes before the addition of purified mucin. Purified mucin $(3 \mu \mathrm{g})$ was incubated with Giardia's secreted products in PBS at $37^{\circ} \mathrm{C}$ for 3 hours. Solutions were resuspended in Laemlli buffer; proteins were separated by electrophoresis (4\% stacking and $7 \%$ resolving gel) and transferred onto nitrocellulose membranes (GE Healthcare, Mississauga, Ontario, Canada). Membranes were incubated with affinitypurified rabbit $\mathrm{IgG}$ mucin antibody, ${ }^{26}$ and bands were visualized with ECL-plus chemiluminescence detection (GE Healthcare). Mucin-specific band intensity (540 kDa) was quantified using ImageJ software. 
Quantification of Mucin mRNA Transcripts in Mouse Tissue and Human Colonic Cells

Total RNA was extracted from $1 \mathrm{~cm}$ of mouse jejunum tissue or LS174T cells using an RNeasy Mini Kit (Qiagen, Montreal, Quebec, Canada) as per manufacturer's instructions. cDNA was synthesized with a QuantiTect Reverse Transcription Kit (Qiagen). RT-PCR was performed using a Rotor Gene-Q (Qiagen). For qPCR with LS174T cells, human MUC2 was normalized to $\beta_{2}$-microglobulin (B2M NM_004048, PPH01094E, RT ${ }^{2}$ qPCR Primer Assay; Qiagen) expression. For qPCR with mouse tissue, murine Muc2 and Muc5ac were normalized to $\beta$ actin expression. All primer sets are listed in Table $1,{ }^{27-31}$ (University Core DNA Services at the University of Calgary, Calgary, Alberta, Canada). Data were analyzed using a $2^{-\Delta \Delta \mathrm{CT}}$ method and expressed as a fold change compared with wild-type (WT) noninfected mice or LS174T cells not exposed to G. duodenalis.

\section{Bacterial Composition Studies}

Total DNA from frozen feces samples were extracted using a DNA Mini Stool Kit (Qiagen) and following a previously published protocol, ${ }^{30}$ with slight modifications. Quantitative RT-PCR was performed with a QuantiFast SYBR green PCR kit (Qiagen) on a Rotor Gene-Q (Qiagen). Primer sets for all bacteria are listed in Table 1 (University Core DNA Services at the University of Calgary). Percent composition of each group was normalized to total $16 \mathrm{~S}$ rRNA quantity (total bacteria).

\section{Statistical Analysis}

All values are expressed as means \pm SEM, unless otherwise noted. Statistical analysis was performed using GraphPad Prism software version 5.0 (GraphPad Software, Inc., San Diego, CA). The normality of the data was assessed before statistical analysis. Differences between groups were assessed using one-way analysis of variance

Table 1 Targets and Primer Sets for RT-PCR

\begin{tabular}{|c|c|}
\hline Target mRNA & Source reference \\
\hline Human MUC2 & Iwashita et $\mathrm{al}^{27}$ \\
\hline \multirow[t]{2}{*}{ Mouse Muc2 } & Fwd: 5'-GAAGCCAGATCCCGAAACCA-3' \\
\hline & Rev: 5'-CCAGCTTGTGGGTGAGGTAG-3' \\
\hline Mouse Muc5ac & Wallace et $\mathrm{al}^{28}$ \\
\hline Mouse B-actin & Osada et $\mathrm{al}^{29}$ \\
\hline Bacteroidetes & Morampudi et $\mathrm{al}^{30}$ \\
\hline Firmicutes & Morampudi et $\mathrm{al}^{30}$ \\
\hline Proteobacteria & Morampudi et $\mathrm{al}^{30}$ \\
\hline $\begin{array}{l}\text { Akkermansia } \\
\text { muciniphila }\end{array}$ & Png et $\mathrm{al}^{31}$ \\
\hline Ruminococcus gnavus & Png et $\mathrm{al}^{31}$ \\
\hline 16s rRNA & Png et $\mathrm{al}^{31}$ \\
\hline
\end{tabular}

with Tukey or Bonferroni multiple comparison's test or two-way analysis of variance with Bonferroni posttests for comparison of three or more groups. For differences between two groups, a $U$-test for comparison of two nonparametric groups or a $t$-test for parametric groups were used.

\section{Results}

G. duodenalis Depletes Intracellular Mucins in Human Intestinal Biopsy Specimens

To determine the effects of G. duodenalis in the human gut, colonic biopsy specimens from healthy donors were exposed to live trophozoites. Human colonic biopsies exposed to $G$. duodenalis trophozoites for 3 hours had reduced intracellular mucin compared with vehicle (PBS)treated controls (Figure 1, A and B). PAS/AB staining revealed that biopsy specimens exposed to $G$. duodenalis contained a mean of $13.25 \% \pm 1.26 \%$ mucous-positive area per crypt, which was significantly lower than the control biopsy specimens $(17.39 \% \pm 1.26 \%$ ) (Figure 1B). These results demonstrate that $G$. duodenalis reduces goblet cell mucin stores in human intestinal tissues.

\section{G. duodenalis Cysteine Proteases Reduce Intracellular Mucins in Human Goblet-Like Cells}

To assess the mechanisms of goblet cell depletion, human LS174T goblet-like cells were exposed to $G$. duodenalis trophozoites over increasing time points at a multiplicity of infection of 20 trophozoites per cell. Infection was associated with an early (20, 40, 60 minutes) decrease of intracellular mucin. After 60 minutes of infection, mucin began to accumulate within the cells (Figure 2, A and B). To investigate the role of Giardia's cysteine proteases in mucin depletion, a broad-spectrum cysteine protease inhibitor (E64) and a specific inhibitor against cathepsin B proteases $(\mathrm{Ca} 074 \mathrm{Me})^{18,19}$ were used. G. duodenalis trophozoites were pretreated with $1 \mu \mathrm{mol} / \mathrm{L}$ E64 or $10 \mu \mathrm{mol} / \mathrm{L} \mathrm{Ca074Me}$ for 30 minutes before cell exposure as previously validated. ${ }^{18,19}$ Pretreatment of Giardia with E64 attenuated intracellular mucin depletion in human goblet-like cells, and pretreatment with $\mathrm{Ca} 074 \mathrm{Me}$ attenuated the mucin depletion at 20 minutes (Figure 2B). Therefore, Giardia's cysteine proteases, at least in part, are responsible for mucin depletion in human goblet cells. These effects may be isolate-specific as Giardia GS/M trophozoites did not induce a significant reduction of intracellular mucins in human LS174T cells (Supplemental Figure S1).

\section{G. duodenalis Depletes Intracellular Mucins through a Cellular PKC and PI3K Signaling Mechanism}

PKC and PI3K are cell-signaling molecules that contribute to physiological mucous secretion pathways. ${ }^{32-35}$ To 
A

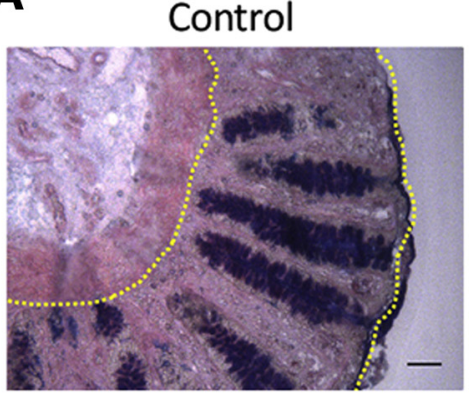

+Giardia

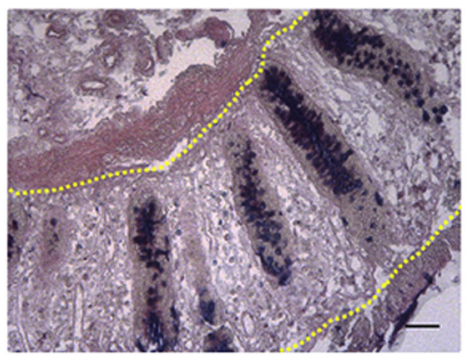

B

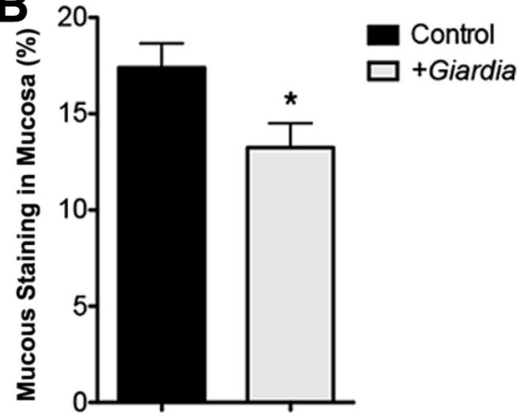

Figure 1 Human colon biopsy specimens incubated ex vivo with Giardia duodenalis contain lower amounts of intracellular mucin. Healthy human colon biopsy specimens were incubated with $G$. duodenalis trophozoites (+Giardia) or phosphate-buffered saline (control) for 3 hours. A: Histologic images of tissues stained with periodic acid-Schiff/Alcian blue (PAS/AB), with the mucosa denoted by a yellow dotted line. B: Specific surface area in the mucosa stained by PAS/AB were quantified using ImageJ software version 1.51. Data are expressed as percentage of mucous staining in colonic mucosa from biopsy specimens of five different patients, using 15 to 17 fields per group. Statistical significance was determined by a $t$-test. Data are expressed as means \pm SEM. ${ }^{\star} P<0.05$. Scale bar $=50 \mu \mathrm{m}$.

determine the role of PKC and PI3K in Giardia-induced mucin depletion, the pharmacologic inhibitors BIM1 $(10 \mu \mathrm{mol} / \mathrm{L})$ and LY294002 (20 $\mu \mathrm{mol} / \mathrm{L})$, respectively, were administered to LS174T cells before Giardia exposure. The inhibition of PKC (Figure 2C) and PI3K (Figure 2D) attenuated the Giardia-induced mucin depletion observed at 20 and 40 minutes, suggesting that PKC and PI3K are implicated in Giardia-induced mucin depletion. A previously established pathogen-induced mucous depletion pathway involves the activation of a host integrin receptor. ${ }^{35}$ LS174T cells were exposed to a function-blocking antibody specific for $\alpha_{\mathrm{v}} \beta_{3}$ integrin, but the data failed to demonstrate a direct role of this integrin in Giardia-induced mucin depletion (Supplemental Figure S2).
A

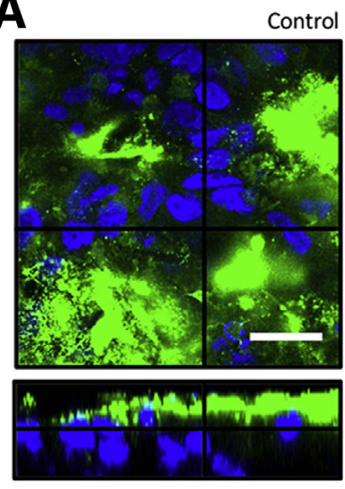

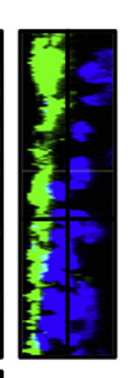

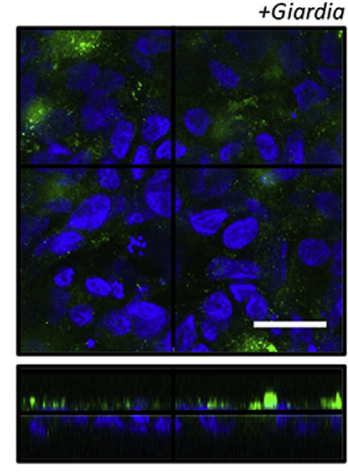

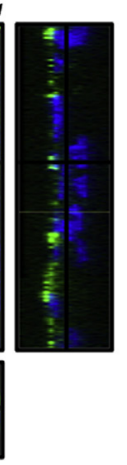
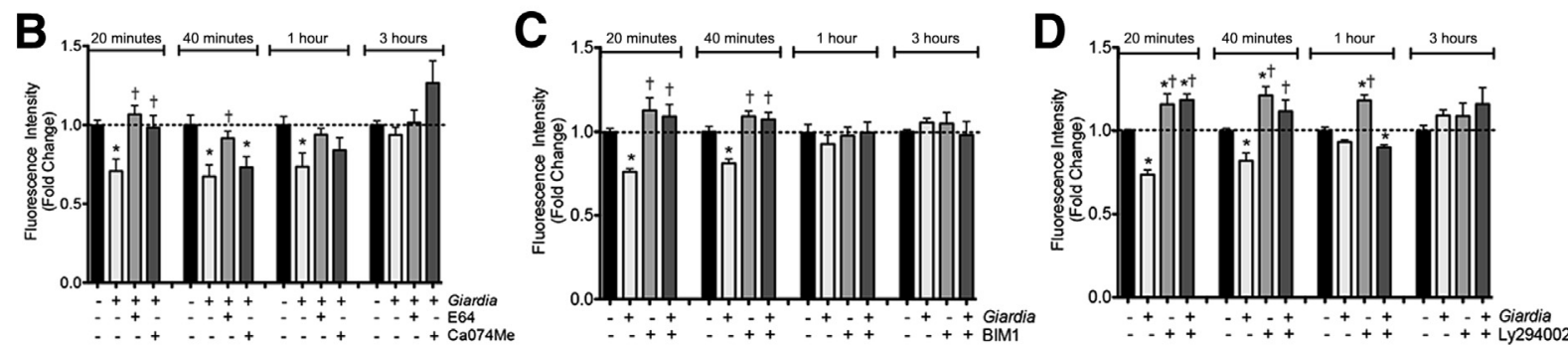

Figure 2 Giardia duodenalis depletes mucin in a human goblet cell line in a cysteine protease-dependent manner. A: Three-dimensional confocal images of LS174T cells infected with $G$. duodenalis trophozoites (+Giardia) or a vehicle control (control) after a 1-hour incubation period. Mucus is stained in green with fluorescein-coupled wheat germ agglutinin (WGA) and DNA in blue with DAPI. B-D: Fluorescence intensity of WGA was quantified and normalized to DAPI. Data are represented as a fold-change compared to cells not exposed to $G$. duodenalis, with a horizontal dashed line representing the control mean of 1.0 units. B: G. duodenalis cells were pretreated for 30 minutes with or without cysteine protease inhibitors E64 or Ca074Me. C and D: LS174T cells were pretreated with or without protein kinase C inhibitor bisindolylmaleimide I (C) or phosphatidylinositol 3-kinase inhibitor Ly294002 (D). Differences between groups were determined by a one-way analysis of variance with a Bonferroni posttest. Data are expressed as means \pm SEM and representative of a minimum of three independent experiments. $n=6$ to 12 per group. ${ }^{\star} P<0.05$ versus control; ${ }^{\dagger} P<0.05$ versus the Giardia-treated group. Scale bar $=20 \mu \mathrm{m}(\mathbf{A}) .+$, inclusion of the substance labeled to the right of the $x$ axis; -, absence of the substance labeled to the right of the $x$ axis. 


\section{G. duodenalis Cysteine Proteases Increase MUC2 Gene Expression in Human Goblet-Like Cells}

In LS174T cells, G. duodenalis exposure was associated with an early (20, 40, 60 minutes) depletion and a later (180 minutes) accumulation of intracellular mucin (Figure 2B). To explore these mechanisms further, MUC2 gene expression was studied in LS174T cells after Giardia exposure. After 60 and 180 minutes of exposure, LS174T cells expressed elevated levels of MUC2 mRNA, with $1.79 \pm 0.30-$ and $2.56 \pm 0.45-$ fold changes from control, respectively (Figure 3). Pretreatment of trophozoites with E64, but not Ca074Me, prevented the increase in MUC2 expression (Figure 3). The data indicate that Giardia's cysteine proteases different from cathepsin B-like proteases are involved in elevated $M U C 2$ gene expression. Giardia's effects on MUC2 expression in LS174T cells may be isolate specific because Giardia GS/M trophozoites did not induce a significant increase in MUC2 in vitro (Supplemental Figure S3).

\section{G. duodenalis Degrades MUC2 Mucin in a Cysteine Protease-Dependent Manner}

To determine whether Giardia's cysteine proteases are capable of degrading mucin, purified human mucin collected from LS174T cells were exposed to G. duodenalis

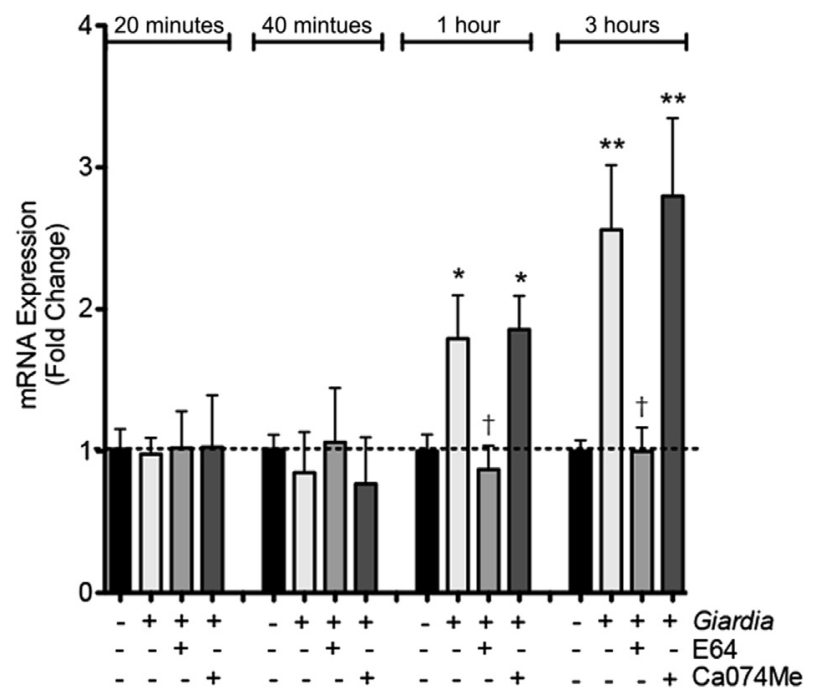

Figure 3 Giardia duodenalis increases Muc2 mRNA expression in a human goblet cell line in a time-dependent manner. LS174T cells were co-incubated with phosphate-buffered saline or $G$. duodenalis trophozoites pretreated with or without cysteine protease inhibitors $\mathrm{E} 64$ or Ca074Me. Muc2 mRNA transcript expression was normalized to $\beta_{2}$-microglobulin. Data are expressed as fold-change compared with their respective time point control, with a horizontal dashed line representing the control mean of 1.0 units. Statistical differences between groups were determined by a one-way analysis of variance with a Bonferroni posttest. Data are expressed as means \pm SEM and representative of a minimum of four independent experiments. $n=8$ to 14 per group. ${ }^{*} P<0.05,{ }^{* *} P<0.01$ versus control; ${ }^{\dagger} P<0.05$ versus Giardia group. + , inclusion of the substance labeled to the right of the $x$ axis; - , absence of the substance labeled to the right of the $x$ axis. secreted products, with or without E64 pretreatment. The results illustrate that Giardia degrades MUC2 in a dosedependent manner because $20 \mu \mathrm{g}$ of Giardia's secreted products decreased the MUC2-specific band intensity to approximately half $(0.588 \pm 0.06$-fold $)$ of the control band, as assessed using Western blot analysis (Figure 4, A and B). Pretreatment of secreted products $(20 \mu \mathrm{g})$ with E64 prevented the degradation of purified human MUC2 (Figure 4, C and D). These results indicate that $G$. duodenalis secretes one or more cysteine proteases that have the capacity to cleave human MUC2.

\section{G. duodenalis Infection in Muc2 $2^{-/-}$Mice Is Associated with Weight Loss and Increased Trophozoite Accumulation in the Small Intestine}

Additional experiments assessed the effects of G. duodenalis on the intestinal mucous layer using a murine model in vivo, first comparing the infection in mucous-deficient $\left(M u c 2^{-1-}\right)$ mice with that in WT C57BL/6 mice. Mice were given $1.0 \times 10^{7}$ live $G$. duodenalis trophozoites via orogastric gavage and studied at day 7 post inoculation. By day 7 post infection, infected WT mice did not have any overt sign of disease and had gained a mean weight that did not significantly differ from that of the WT noninfected group (Figure 5A). In contrast, at day 7 post infection, infected $\mathrm{Muc}^{-/-}$mice lost a mean of $1.33 \% \pm 1.14 \%$ of their body weight, whereas noninfected $\mathrm{Muc}^{-/-}$mice gained a mean of $5.77 \% \pm 1.14 \%$ of their body weight (Figure 5A). Furthermore, infected $M u c 2^{-1-}$ mice harbored a significantly larger number of trophozoites in their jejunum compared with infected WT mice (Figure 5B). Trophozoite numbers in the colons of both the $M u c 2^{-1-}$ and WT mice were below the detection limit of the assay (data not shown). These results indicate that the mucous layer helps protect the host intestine against $G$. duodenalis colonization.

Mice Infected with $G$. duodenalis Have Heightened Levels of Intracellular Mucin and a Thinner Mucous Layer

The effects of G. duodenalis on the intestinal mucous layer were visualized in vivo, in the mouse colon, where the mucous layer is the thickest and consistent with recent observations that Giardia may affect the large and small intestines. ${ }^{36}$ In WT mice, G. duodenalis infection significantly reduced the thickness of the mucous layer compared with noninfected controls (Figure 6, A and B). Infected mice had a higher density of WGA-positive staining within the goblet cells compared with noninfected mice (Figure 6, $\mathrm{A}$ and $\mathrm{C}$ ). These results indicate that $G$. duodenalis infection in vivo is associated with reduction of mucous layer thickness and stimulation of goblet cell mucin production. 

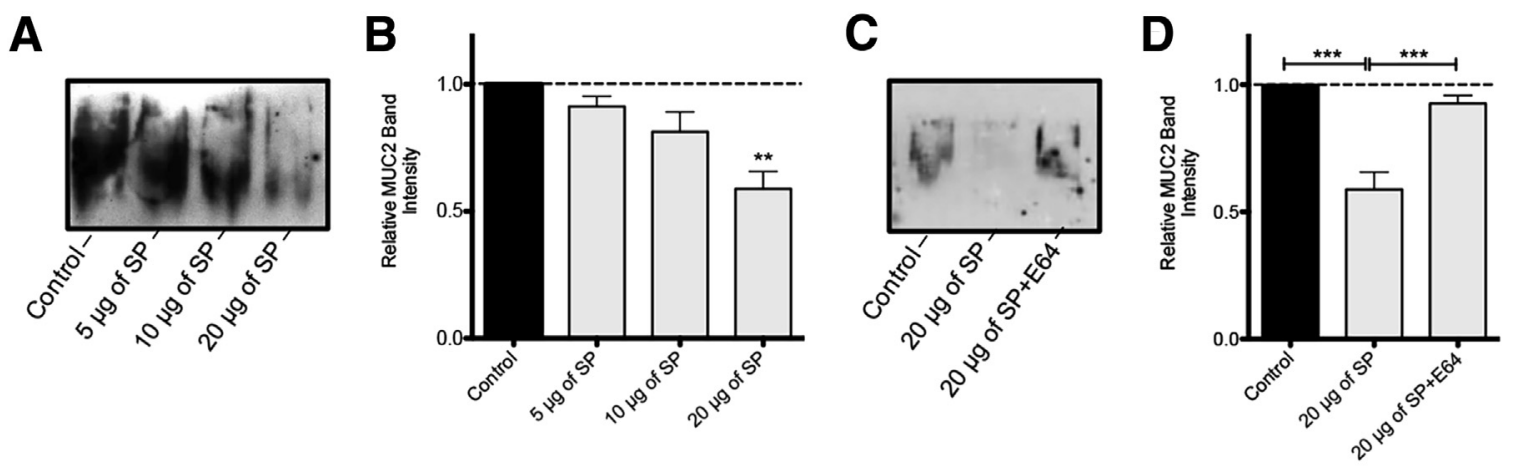

Figure 4 Giardia duodenalis cysteine proteases degrade human MUC2 mucin in a dose-dependent manner. A and B: Increasing concentrations of secreted products (SP) were incubated with $3 \mu \mathrm{g}$ of purified human MUC2 for 3 hours. C and D: SP were preincubated with cysteine protease inhibitor E64 before incubation with $3 \mu \mathrm{g}$ of purified human MUC2. A and C: Total proteins were separated by electrophoresis ( $4 \%$ stacking gel), and MUC2 protein was detected by Western blot analysis. B and D: Intensity of MUC2-specific bands were quantified and expressed as fold-change to a nontreated control (0 $\mu \mathrm{g}$ of SP), with a horizontal dashed line representing the control mean of 1.0 unit. B: Statistical significance between each group was compared to the control using a $t$-test. D: Statistical significance between each of the groups was determined by a one-way analysis of variance with Tukey's multiple comparisons posttest. Data are expressed as means \pm SEM and representative images of blots performed in three to four independent experiments. ${ }^{* *} P<0.01,{ }^{* * *} P<0.001$.

\section{G. duodenalis Infection Induces Differential Mucin Gene Expression in the Gastrointestinal Tract}

In human LS174T goblet-like cells, Giardia increased MUC2 gene expression after 180 minutes (Figures $2 \mathrm{~B}$ and 3). To assess whether this stimulatory effect occurred in vivo, mucin gene expression was determined by quantitative RTPCR in mice. In the colon, Giardia infection significantly increased Muc2 and Muc5ac mRNA expression (Figure 7A). Muc6 mRNA expression was also evaluated but was not observed in the small intestine or colon. Compared with noninfected mice, after 7 days of infection, Muc2 and Muc5ac mRNA were increased $2.60 \pm 0.52-$ and $4.43 \pm 0.70$-fold, respectively (Figure 7A). The increase in Muc2 expression was not observed in the jejunum, where colonization by Giardia trophozoites is high (Figure 7B). In contrast, Giardia infection significantly increased Muc5ac expression in the jejunum (Figure 7B). Infected $\mathrm{Muc2}^{-1-}$ animals failed to exhibit significant changes in mucin expression in the colon (Figure 7C) or in the jejunum (Figure 7D). These results indicate that G. duodenalis infection in vivo is associated with differential mucin gene expression in the small and large intestine.

\section{G. duodenalis Infection Is Associated with Increased Bacterial Translocation}

To assess whether the observed disruptions in the mucous barrier during $G$. duodenalis infection were associated with loss of barrier function, experiments were performed to characterize bacterial translocation across the gut wall. In WT mice, Giardia infection induced significant bacterial translocation through the intestinal epithelium (Figure 8A) and into the liver (Figure 8B) and spleen (Figure 8C). WT mice infected with $G$. duodenalis contained significantly higher numbers of aerobic and anaerobic bacteria in their liver and spleen compared with noninfected controls. Bacterial translocation in infected $M u c 2^{-/-}$mice was not significantly different than in the noninfected controls (Figure 8, D and E). The results indicate that the mucous

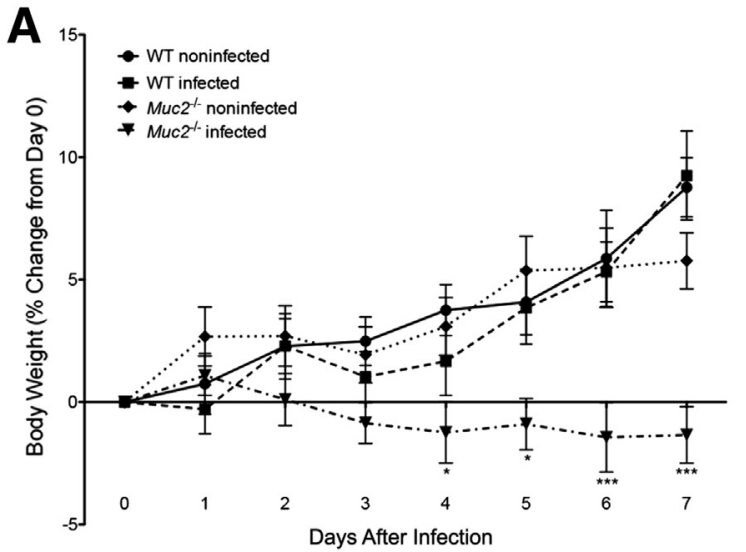

B

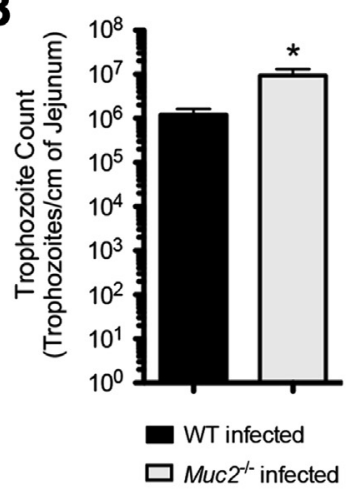

Figure 5 Giardia duodenalis infection in Muc2 $^{-/-}$mice is associated with weight loss and increased trophozoite counts in the small intestine. C57BL/6 [wild-type (WT)] and Muc2 ${ }^{-1-}$ mice were gavaged with $1.0 \times 10^{7} \mathrm{G}$. duodenalis trophozoites (infected) or vehicle control (noninfected). A: Weight is expressed as percent change of weight from day 0 . Two-way analysis of variance and Bonferroni multiple comparisons posttest were used to determine significant differences from the WT noninfected group. B: Trophozoites in the proximal jejunum were enumerated. No trophozoites were observed in the noninfected mice (data not shown). Statistical significance between groups was analyzed by Mann-Whitney $t$-test. Data are expressed as means \pm SEM and representative of five independent experiments. $n=15$ to 30 mice per group. ${ }^{*} P<0.05,{ }^{* *} P<0.001$. 

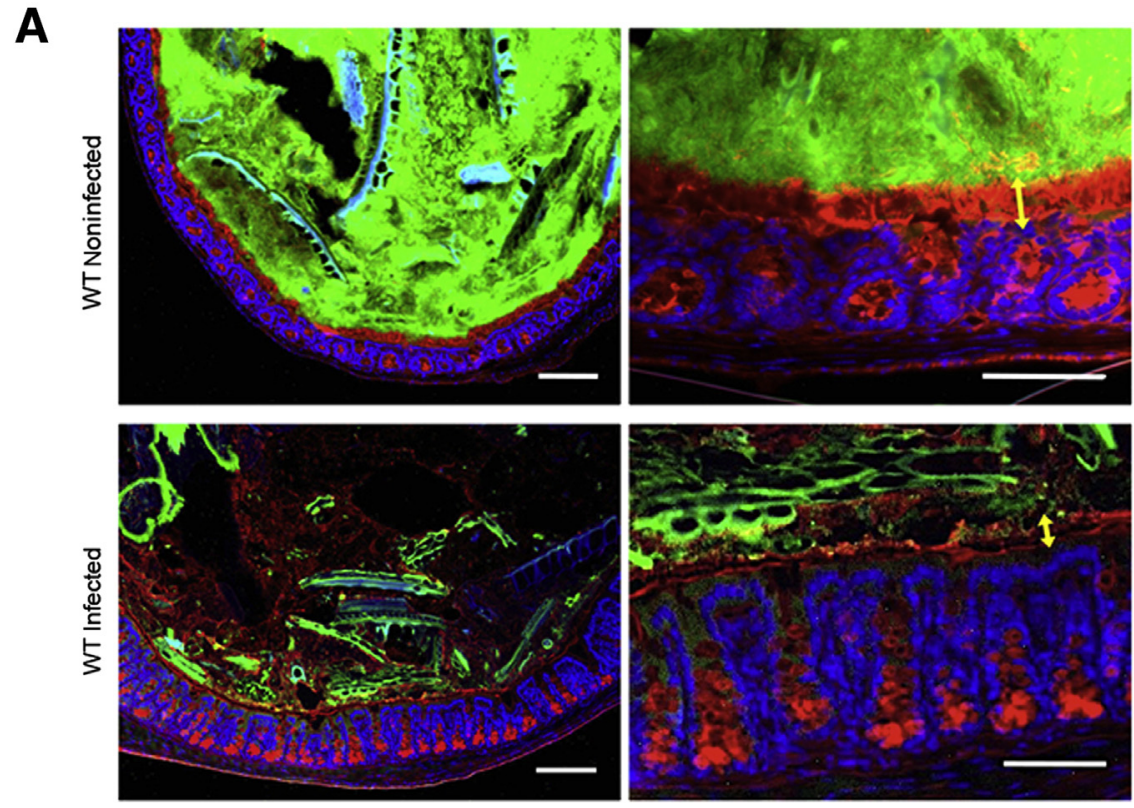

Figure 6 Mice infected with Giardia duodenalis have enlarged goblet cells and a thinner mucous layer. C57BL/6 [wild-type (WT)] mice were gavaged with $1.0 \times 10^{7} \mathrm{G}$. duodenalis trophozoites (infected) or vehicle control (noninfected). A: Fluorescent microscopic images of mouse colon on day 7 after infection. Intestinal bacteria were stained in green with fluorescent in situ hybridization (EUB338-Cy3 probe), mucus in red with fluorescein-coupled wheat germ agglutinin (WGA), and cell nuclei in blue with DAPI. B: Mucous layer thickness (defined by the yellow arrows in $\mathbf{A}$ ) was measured using ImageJ software version 1.51 . Measurements were taken from a minimum of three different microscopic fields from two to five images per animal, measuring the thickness of the WGA stain. C: Fluorescence intensity of WGA signal within the crypts was quantified with ImageJ software. Measurements were taken from a minimum of three crypts from two to five images per animal. The horizontal dashed line represents the control mean of 1.0 units. Data are expressed as means \pm SEM. $n=6$ to 8 mice per group. Statistical significance between groups was determined by a Mann-Whitney $t$-test. ${ }^{*} P<0.05$, ${ }^{* *} P<0.01$. Scale bars: $100 \mu \mathrm{m}$ in (A, left images); $500 \mu \mathrm{m}$ (A, right images).

disruption induced by $G$. duodenalis infection is associated with increased translocation of commensal bacteria.

\section{Discussion}

The results of this study unravel novel pathophysiologic mechanisms whereby an enteric pathogen evades and alters mucus in the small and large intestine. Concurrently, the findings reveal a host response of differential mucin gene expression induced by intestinal infection. The mucous layers of the small and large intestines are designed to provide an effective barrier against enteropathogenic infection and subsequent disease and are important for commensal bacteria establishment. ${ }^{11-14}$ This study demonstrates how $G$. duodenalis infection can degrade MUC2 protein in a cysteine protease-dependent manner and subsequently deplete mucin stores and induce differential mucin gene expression. These disruptions are associated with facilitated bacterial translocation, an effect that has been implicated in a variety of gastrointestinal disorders. ${ }^{12,14-16,36-38}$

These findings further highlight a protective role for mucus against $G$. duodenalis infection, consistent with earlier suggestions that intestinal mucus may interfere with trophozoite attachment and colonization. ${ }^{39,40}$ The present results indicate that lack of the $M u c 2$ gene in mice infected with $G$. duodenalis allows high colonization of trophozoites associated with significant weight loss.

The human relevance of the present findings was further demonstrated in human biopsy specimens, using an experimental protocol validated recently. ${ }^{18}$ Indeed, colonic biopsy specimens exposed to G. duodenalis for 3 hours exhibited a reduction in mucin content in the epithelium. In human goblet-like cells exposed to G. duodenalis in vitro, mucin depletion occurred at early time points, whereas increased intracellular mucin at later time points was associated with an increase in MUC2 mRNA expression. These observations are consistent with previous reports that mucous secretion in response to a secretagogue occurs within minutes, increased mucin gene expression is seen in a period of hours, and mucin biosynthesis follows later. ${ }^{41-43}$ Importantly, both mucin depletion and increased MUC2 mRNA expression in response to Giardia were inhibited with the broad-spectrum cysteine protease inhibitor (E64), revealing a critical role for Giardia proteases in pathophysiology. Ca074Me and E64, used at the concentrations described here, have been previously found to inhibit 

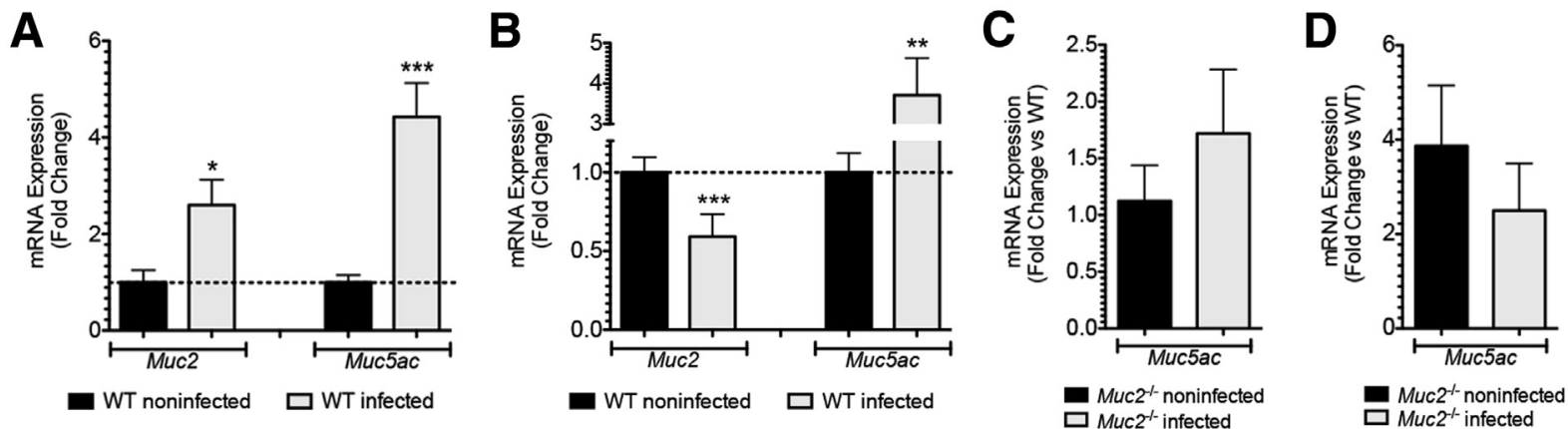

Figure 7 Giardia duodenalis infection induces differential mucin gene expression in mice. C57BL/6 [wild-type (WT)] (A and B) and Muc2 ${ }^{-/-}$(C and $\left.\mathbf{D}\right)$ mice were gavaged with $1.0 \times 10^{7} \mathrm{G}$. duodenalis trophozoites (infected) or vehicle control (noninfected). Muc2 and Muc5ac mRNA transcript expression in colon (A and $\mathbf{C}$ ) and jejunum (B and $\mathbf{D}$ ), normalized to $\beta$-actin mRNA. Muc2 mRNA expression is not shown for Muc2 ${ }^{-1-}$ mice as none was detected. All data are expressed as fold change compared with WT noninfected mice, with a horizontal dashed line representing the control mean of 1.0 unit. Statistical differences compared with noninfected controls were determined by a Mann-Whitney $t$-test. Data are expressed as means \pm SEM and representative of five independent experiments. $n=15$ to 30 mice per group. ${ }^{*} P<0.05,{ }^{* *} P<0.01$, and ${ }^{* * *} P<0.001$.

Giardia's cysteine proteases and specific cathepsin B proteases, respectively, without affecting Giardia viability. ${ }^{18,19,44}$ In the present study, E64 but not Ca074Me inhibited Giardia-induced mucin depletion, suggesting that this effect was attributable to parasite cysteine proteases other than cathepsin B-like proteases. Finally, the present findings indicate that Giardia stimulates mucous depletion in goblet-like cells by signaling through PKC and PI3K pathways known to play key roles in physiologic mucous secretion. ${ }^{32-35}$ Experiments also investigated whether the $\alpha_{v} \beta_{3}$ integrin played a role in the Giardia-induced mucin regulation using a recently validated blocking antibody. ${ }^{35}$ These data failed to demonstrate a role for this integrin, in contrast with the recent studies on Entamoeba histolytica. ${ }^{35}$ While supporting the hypothesis that these two processes may occur via different signaling pathways, the observations indicate that additional research is needed to characterize the mechanisms of how Giardia proteases regulate host intestinal mucin production upstream of PKC and PI3K.

Giardia's cysteine proteases have been recently implicated in disruptions of epithelial cytoskeletal villin, ${ }^{19}$
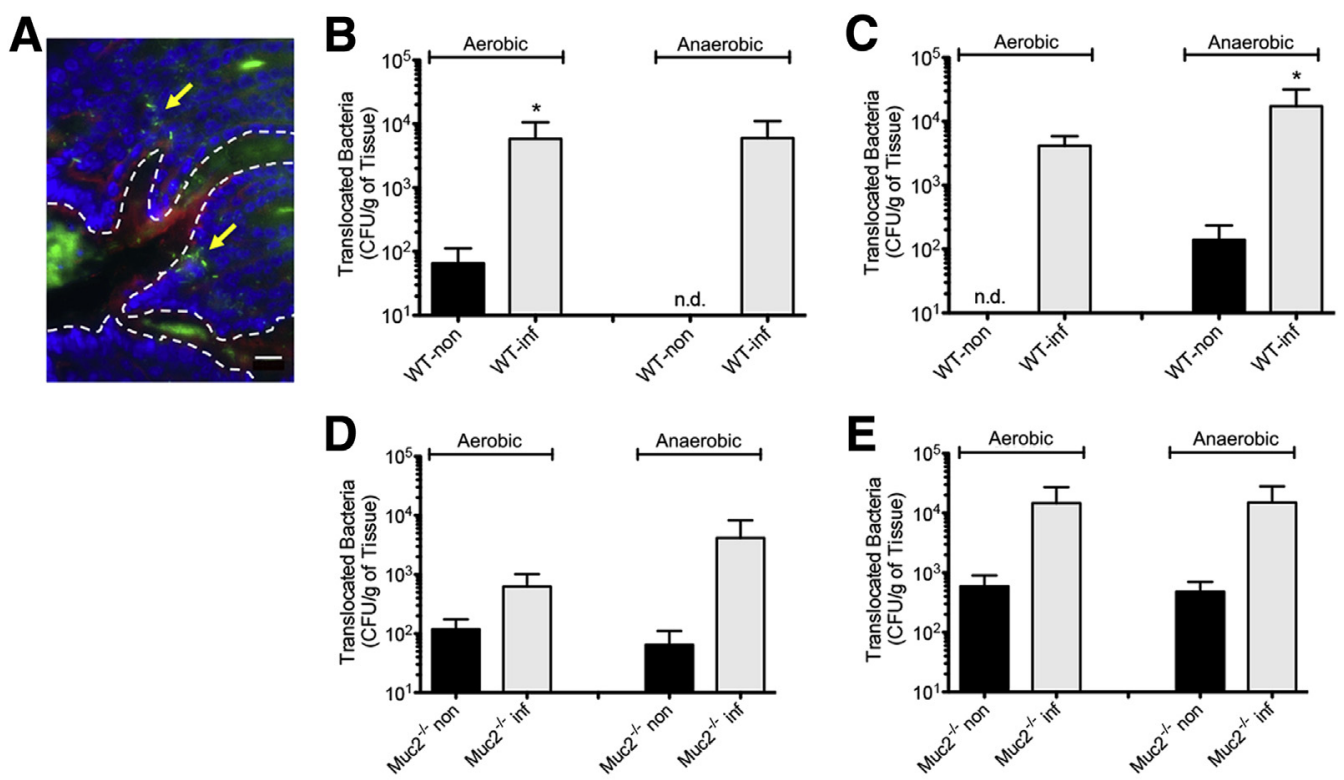

Figure 8 Giardia-induced disruptions to the mucous barrier facilitate bacterial translocation. C57BL/6 [wild-type (WT)] and Muc2 ${ }^{-/-}$mice were gavaged with $1.0 \times 10^{7} \mathrm{G}$. duodenalis trophozoites [infected (inf)] or vehicle control [noninfected (non)]. A: Intestinal bacteria in WT infected mouse colon were stained in green with fluorescent in situ hybridization (EUB338-Cy3 probe), mucus in red with fluorescein-coupled wheat germ agglutinin, and cell nuclei in blue with DAPI. The limit between the lumen and the intestinal epithelium is denoted by a dashed white line, with yellow arrows indicating translocated bacteria into submucosa. Bacteria invaded the liver (B and $\mathbf{D}$ ) and spleen (C and $\mathbf{E})$ of WT (B and $\mathbf{C}$ ) and Muc2 ${ }^{-/-}$(D and $\left.\mathbf{E}\right)$ mice, cultured on $5 \%$ Columbia blood agar plates under aerobic and anaerobic conditions for 48 hours. Data are expressed in colony-forming units per gram of tissue. Statistical significance between groups was determined by a Mann-Whitney $t$-test. Data are expressed as means \pm SEM. $n=11$ to 12 mice per group. ${ }^{\star} P<0.05$. Scale bar $=10 \mu \mathrm{m}$ (A). n.d., not detected. 
alterations of human intestinal microbiota biofilms, ${ }^{45}$ degradation of host innate immune mediators, ${ }^{18}$ and mechanisms involved in their own survival, proliferation, and cyst formation. ${ }^{17}$ Results from the present study uncovered further mechanisms of Giardia's cysteine protease activity, including mucin degradation, depletion, and alteration of mucin gene expression. Cysteine proteases have been implicated in the pathogenesis of other parasitic species, including the protozoan parasite E. histolytica, which secretes a cysteine protease that cleaves MUC2 mucin to dissolve the protective colonic mucus layer. ${ }^{15}$ Furthermore, a cysteine protease, cruzipain, secreted by Trypanosoma cruzi, the parasitic agent responsible for Chagas disease, is essential for virulence, transmission, and survival. ${ }^{46}$ Inhibitors of cruzipain have been effective in preclinical models and show promise as a chemotherapeutic treatment against Chagas disease. ${ }^{46,47}$ Indeed, preliminary studies indicate that cysteine protease inhibitors may be efficacious in the treatment of parasites, including Plasmodium falciparum $^{48}$ and Leishmania species. ${ }^{49}$ Results from the present study underline the importance of $G$. duodenalis cysteine proteases in contribution to disease, making them potential targets for the development of future therapeutics.

G. duodenalis, Campylobacter species Escherichia coli, Salmonella species, and Shigella species, among others, are implicated in postinfectious chronic IBS; however, the pathophysiologic mechanisms underlying the onset and propagation of chronic illnesses after acute infection remains unknown. ${ }^{50,51}$ The role of the mucous layer in the pathologic mechanisms surrounding these organisms requires further elucidation. The data presented here show that G. duodenalis reduces mucous thickness in association with cysteine protease-mediated degradation of MUC2. Mucus disruption was observed in the colon, a site most often devoid of Giardia trophozoites during infection, indicating that live trophozoites may not be required to alter intestinal mucus. Indeed, the present studies demonstrate that Giardia-secreted products alone were able to degrade MUC2. Importantly, these results demonstrate that G. duodenalis, and its secreted proteases, may have direct and indirect effects in the site of colonization and in distal locations, such as the large intestine. Giardia's secreted cysteine proteases may directly degrade the thick mucous layer in the colon and have indirect effects on the goblet cells, altering mucin secretion rates to induce goblet cell mucin depletion and altering expression of mucin genes. Indeed, these results are in accordance with previous studies, which demonstrate that Giardia can induce pathophysiologic effects in distal locations to the site of colonization, in the form of parasiteinduced visceral hypersensitivity in the rectum and jejunum. ${ }^{36}$ The present studies did not detect any significant changes in key tissue cytokines concurrent with the mucous effects (Supplemental Figure S4), indicating that mucous disruptions distal to parasite colonization are likely not host immune mediated. In addition, overall goblet cell numbers within the jejunum and colon remained unchanged
(Supplemental Figure S5), indicating that the changes in mucin content were not attributable to goblet cell hyperplasia, as described in nematode infections, ${ }^{52}$ or to a depletion of mucin-producing cells. Because Giardia's mucous disruptions have been observed to be cysteine protease mediated and independent of cell contact, further research is warranted to determine the exact mechanisms of mucous disruption distal to the site of parasite colonization.

Importantly, this study also demonstrates that the gastric/ respiratory Muc5ac gene may be induced in the intestine in response to enteric infection. Consistent with this hypothesis, Muc5ac mRNA was increased in the jejunum and colon of infected mice. Further research is warranted to determine whether this potential compensatory mechanism is similar to the induction of Muc5ac in response to the Muc2-degrading Trichuris muris. ${ }^{16}$ Human mucins are not easily purified or obtained commercially. MUC5AC is similar to MUC2 in its protein core but may pose as a greater challenge for proteolysis because of its higher number of cysteine domains ( 2 cysteine domains in MUC2 compared with 11 domains in MUC5 $\mathrm{AC}^{12}$ ), which in turn enhances folding and crosslinking, lending to higher mucous viscosity. ${ }^{53}$ Indeed, transgenic addition of cysteine domains into mouse mucosal secretions has been described as a potential method to decrease mucolytic activity and prevent enteropathogenic infection. ${ }^{53}$ Of note, PKC has been proposed to mediate enhanced expression of MUC2 and differential expression of MUC5AC in shigellosis, ${ }^{54}$ and both PI3K and PKC are important signaling molecules in the gene expression of airway mucins ${ }^{33}$; therefore, further research is warranted to determine the downstream signaling involved in Giardiainduced mucous expression.

Recent findings have described Giardia's ability to alter the composition and structure of human gut microbiota biofilms ${ }^{45}$ and to promote the formation of pathobionts, which in turn cause host pathologic conditions. ${ }^{55}$ FISH staining in the present study revealed that the dense microbiota biofilm seen in the colon of noninfected mice had a much less compact structure in mice infected with $G$. duodenalis (Figure 6A). Similar staining failed to reveal any significant microbiota biofilm structure in the jejunum (data not shown). To determine whether the changes reported herein may be associated with altered representation of mucolytic and/or nonmucolytic microbiota bacteria, ${ }^{37}$ RTPCR analyses for selected bacteria were performed. This approach failed to identify overt alterations in the relative abundance of these species (Supplemental Figure S6). More research is needed to assess whether alterations in mucus during Giardia infection may also reflect alterations in microbiota taxonomic profiles as reported recently ${ }^{45}$ and, perhaps even more importantly, disrupted microbiota metabolomes.

Results from the present study demonstrate transepithelial migration of commensal bacteria into the liver and spleen of infected WT mice and in animals that lack the $M u c 2$ gene. These observations are in accordance with 
previous studies that demonstrate bacterial overgrowth and translocation after $G$. duodenalis infection. ${ }^{36,38}$ Although the current study investigated the effects of an impaired mucous barrier during acute infection, other studies have indicated that barrier disruption may persist after infection, demonstrating bacterial adherence and penetration of commensal microbiota in the small intestinal and colonic epithelium 35 and 50 days post infection. ${ }^{36,38}$ Importantly, giardiasis impairs epithelial barrier function by disrupting apical junction complex proteins, including zonula occluden-1, occludin, F-actin, $\alpha$-actinin, E-cadherin, and claudins- 1 and $-4 .{ }^{36,56-58}$

An impaired mucous barrier, in conjunction with previously described observations of Giardia-induced epithelial barrier dysfunction, ${ }^{36,56-58}$ leads to bacterial penetration into the liver and spleen of infected mice. Bacterial overgrowth and translocation have been reported to induce inflammation correlated with several gastrointestinal disorders. ${ }^{59}$ Despite an impaired mucosal barrier and bacteria penetration, G. duodenalis infection is not associated with overt inflammation, excluding a minor increase in intraepithelial lymphocytes, consistent with the potent immunomodulating effects of the parasite. ${ }^{60}$ Indeed, recent studies indicate that $G$. duodenalis impairs the host inflammatory response by degradation of various proinflammatory mediators, including the neutrophil chemoattractant, CXCL8. ${ }^{18}$ G. duodenalis was also reported to ameliorate inflammation in Clostridium difficile-induced colitis in mice and to attenuate tissue contents of proinflammatory mediators in human biopsy specimens from patients with Crohn disease. ${ }^{22}$ Therefore, the current study describes a novel mechanism whereby $G$. duodenalis evades and alters the host innate defenses of the mucous layer, leading to bacterial translocation and thwarting an overt immune response.

In summary, the results of this study demonstrate that in response to intestinal infection with $G$. duodenalis, differential gene expression of Muc5ac and Muc2 is induced in the small and large intestine in association with parasiteinduced degradation of the MUC2 protein and depletion of goblet cell mucin stores. Consistent with these disruptions of the protective mucous lining, which affected both the jejunum and colon, mice infected with Giardia showed signs of transepithelial invasion by commensal bacteria and contained aerobic and anaerobic bacteria in their liver and spleen. Mechanistic studies then found that $G$. duodenalis uses cysteine proteases to degrade secreted MUC2 protein. Giardia's cysteine proteases were also responsible for the mucin depletion from goblet cells and the altered mucin gene expression. Muc $2^{-/-}$mice infected with $G$. duodenalis were colonized by higher numbers of trophozoites and suffered from significant weight loss, further highlighting the protective significance of mucus during $G$. duodenalis infections. Overall, these studies unravel novel pathophysiologic mechanisms of enteric infection, including mucous alteration and degradation. Future studies will explore how such effects could contribute to chronic gastrointestinal illnesses after acute bouts of enteric infections.

\section{Acknowledgments}

We thank the Inflammation Tissue Bank at the University of Calgary for providing human biopsy specimens and Troy Feener at the University of Calgary for his assistance with the mouse studies.

C.B.A., J.-P.M., A.G.B., and K.C. conceived and designed the experiments; C.B.A., J.-P.M., E.F., and F.M. performed the experiments and analyzed the data; K.C. and A.G.B. contributed reagents and materials; C.B.A., J.-P.M., and A.G.B. wrote the manuscript; A.G.B. is the guarantor of this work and, as such, had full access to all the data in the study and takes responsibility for the integrity of the data and the accuracy of the data analysis.

\section{Supplemental Data}

Supplemental material for this article can be found at http://dx.doi.org/10.1016/j.ajpath.2017.07.009.

\section{References}

1. Savioli L, Smith H, Thompson A: Giardia and Cryptosporidium join the 'Neglected Diseases Initiative'. Trends Parasitol 2006, 22 203-208

2. Olson ME, McAllister TA, Deselliers L, Morck DW, Cheng KJ, Buret AG, Ceri H: Effects of giardiasis on production in a domestic ruminant (lamb) model. Am J Vet Res 1995, 56:1470-1474

3. Geurden T, Vercruysse J, Claerebout E: Is Giardia a significant pathogen in production animals? Exp Parasitol 2010, 124:98-106

4. Halliez MC, Buret AG: Extra-intestinal and long term consequences of Giardia duodenalis infections. World J Gastroenterol 2013, 19: 8974-8985

5. Platts-Mills JA, Babji S, Bodhidatta L, Gratz J, Haque R, Havt A, et al; MAL-ED Network Investigators: Pathogen-specific burdens of community diarrhoea in developing countries: a multisite birth cohort study (MAL-ED). Lancet Glob Health 2015, 3:e564-e575

6. Hanevik K, Dizdar V, Langeland N, Hausken T: Development of functional gastrointestinal disorders after Giardia lamblia infection. BMC Gastroenterol 2009, 9:27

7. Nygard K, Schimmer B, Sobstad O, Walde A, Tveit I, Langeland N, Hausken T, Aavitsland P: A large community outbreak of waterborne giardiasis-delayed detection in a non-endemic urban area. BMC Public Health 2006, 6:141

8. Pasupuleti V, Escobedo AA, Deshpande A, Thota P, Roman Y, Hernandez AV: Efficacy of 5-nitroimidazoles for the treatment of giardiasis: a systematic review of randomized controlled trials. PLoS Neg1 Trop Dis 2014, 8:e2733

9. Ansell BR, McConville MJ, Ma'ayeh SY, Dagley MJ, Gasser RB, Svard SG, Jex AR: Drug resistance in Giardia duodenalis. Biotechnol Adv 2015, 33:888-901

10. Upcroft P, Upcroft JA: Drug targets and mechanisms of resistance in the anaerobic protozoa. Clin Microbiol Rev 2001, 14:150-164

11. Johansson ME, Phillipson M, Petersson J, Velcich A, Holm L, Hansson GC: The inner of the two Muc2 mucin-dependent mucus layers in colon is devoid of bacteria. Proc Natl Acad Sci U S A 2008 , 105:15064-15069 
12. Johansson ME, Sjovall H, Hansson GC: The gastrointestinal mucus system in health and disease. Nat Rev Gastroenterol Hepatol 2013, 10:352-361

13. Forstner G: Signal transduction, packaging and secretion of mucins. Annu Rev Physiol 1995, 57:585-605

14. Birchenough GM, Johansson ME, Gustafsson JK, Bergstrom JH, Hansson GC: New developments in goblet cell mucus secretion and function. Mucosal Immunol 2015, 8:712-719

15. Lidell ME, Moncada DM, Chadee K, Hansson GC: Entamoeba histolytica cysteine proteases cleave the MUC2 mucin in its C-terminal domain and dissolve the protective colonic mucus gel. Proc Natl Acad Sci U S A 2006, 103:9298-9303

16. Hasnain SZ, McGuckin MA, Grencis RK, Thornton DJ: Serine protease(s) secreted by the nematode Trichuris muris degrade the mucus barrier. PLoS Negl Trop Dis 2012, 6:e1856

17. DuBois KN, Abodeely M, Sakanari J, Craik CS, Lee M, McKerrow JH, Sajid M: Identification of the major cysteine protease of Giardia and its role in encystation. J Biol Chem 2008, 283: 18024-18031

18. Cotton JA, Bhargava A, Ferraz JG, Yates RM, Beck PL, Buret AG: Giardia duodenalis cathepsin B proteases degrade intestinal epithelial interleukin-8 and attenuate interleukin-8-induced neutrophil chemotaxis. Infect Immun 2014, 82:2772-2787

19. Bhargava A, Cotton JA, Dixon BR, Gedamu L, Yates RM, Buret AG: Giardia duodenalis surface cysteine proteases induce cleavage of the intestinal epithelial cytoskeletal protein villin via myosin light chain kinase. PLoS One 2015, 10:e136102

20. Lauwaet T, Andersen Y, Van de Ven L, Eckmann L, Gillin FD: Rapid detachment of Giardia lamblia trophozoites as a mechanism of antimicrobial action of the isoflavone formononetin. J Antimicrob Chemother 2010, 65:531-534

21. Keister DB: Axenic culture of Giardia lamblia in TYI-S-33 medium supplemented with bile. Trans R Soc Trop Med Hyg 1983, 77 : 487-488

22. Cotton JA, Motta JP, Schenck LP, Hirota SA, Beck PL, Buret AG: Giardia duodenalis infection reduces granulocyte infiltration in an in vivo model of bacterial toxin-induced colitis and attenuates inflammation in human intestinal tissue. PLoS One 2014, 9: e109087

23. Velcich A, Yang W, Heyer J, Fragale A, Nicholas C, Viani S, Kucherlapati R, Lipkin M, Yang K, Augenlicht L: Colorectal cancer in mice genetically deficient in the mucin Muc2. Science 2002, 295: $1726-1729$

24. Cobo ER, Kissoon-Singh V, Moreau F, Chadee K: Colonic MUC2 mucin regulates the expression and antimicrobial activity of betadefensin 2. Mucosal Immunol 2015, 8:1360-1372

25. Motta JP, Flannigan KL, Agbor TA, Beatty JK, Blackler RW, Workentine ML, Da Silva GJ, Wang R, Buret AG, Wallace JL: Hydrogen sulfide protects from colitis and restores intestinal microbiota biofilm and mucus production. Inflamm Bowel Dis 2015, 21: 1006-1017

26. Belley A, Keller K, Grove J, Chadee K: Interaction of LS174T human colon cancer cell mucins with Entamoeba histolytica: an in vitro model for colonic disease. Gastroenterology 1996, 111:1484-1492

27. Iwashita J, Sato Y, Sugaya H, Takahashi N, Sasaki H, Abe T: mRNA of MUC2 is stimulated by IL-4, IL-13 or TNF-alpha through a mitogen-activated protein kinase pathway in human colon cancer cells. Immunol Cell Biol 2003, 81:275-282

28. Wallace JL, Vong L, Dharmani P, Srivastava V, Chadee K: Muc-2deficient mice display a sex-specific, COX-2-related impairment of gastric mucosal repair. Am J Pathol 2011, 178:1126-1133

29. Osada T, Uehara H, Kim H, Ikai A: mRNA analysis of single living cells. J Nanobiotechnology 2003, 1:2

30. Morampudi V, Dalwadi U, Bhinder G, Sham HP, Gill SK, Chan J, Bergstrom KS, Huang T, Ma C, Jacobson K, Gibson DL, Vallance BA: The goblet cell-derived mediator RELM-beta drives spontaneous colitis in Muc2-deficient mice by promoting commensal microbial dysbiosis. Mucosal Immunol 2016, 9:1218-1233

31. Png CW, Linden SK, Gilshenan KS, Zoetendal EG, McSweeney CS, Sly LI, McGuckin MA, Florin TH: Mucolytic bacteria with increased prevalence in IBD mucosa augment in vitro utilization of mucin by other bacteria. Am J Gastroenterol 2010, 105:2420-2428

32. Adler KB, Tuvim MJ, Dickey BF: Regulated mucin secretion from airway epithelial cells. Front Endocrinol (Lausanne) 2013, 4:129

33. Kim YD, Jeon JY, Woo HJ, Lee JC, Chung JH, Song SY, Yoon SK, Baek SH: Interleukin-1beta induces MUC2 gene expression and mucin secretion via activation of PKC-MEK/ERK, and PI3K in human airway epithelial cells. J Korean Med Sci 2002, 17:765-771

34. Forstner G, Zhang Y, McCool D, Forstner J: Mucin secretion by T84 cells: stimulation by $\mathrm{PKC}, \mathrm{Ca} 2+$, and a protein kinase activated by Ca2+ ionophore. Am J Physiol 1993, 264:G1096-G1102

35. Cornick S, Moreau F, Chadee K: Entamoeba histolytica cysteine proteinase 5 evokes mucin exocytosis from colonic goblet cells via alphavbeta3 integrin. PLoS Pathog 2016, 12:e1005579

36. Halliez MC, Motta JP, Feener TD, Guerin G, LeGoff L, Francois A, Colasse E, Favennec L, Gargala G, Lapointe TK, Altier C, Buret AG: Giardia duodenalis induces paracellular bacterial translocation and causes postinfectious visceral hypersensitivity. Am J Physiol Gastrointest Liver Physiol 2016, 310:G574-G585

37. Buret AG: Enteropathogen-induced microbiota biofilm disruptions and post-infectious intestinal inflammatory disorders. Curr Trop Med Rep 2016, 3:94-101

38. Chen TL, Chen S, Wu HW, Lee TC, Lu YZ, Wu LL, Ni YH, Sun $\mathrm{CH}$, Yu WH, Buret AG, Yu LC: Persistent gut barrier damage and commensal bacterial influx following eradication of Giardia infection in mice. Gut Pathog 2013, 5:26

39. Roskens H, Erlandsen SL: Inhibition of in vitro attachment of Giardia trophozoites by mucin. J Parasitol 2002, 88:869-873

40. Muller N, von Allmen N: Recent insights into the mucosal reactions associated with Giardia lamblia infections. Int J Parasitol 2005, 35: $1339-1347$

41. Verdugo P: Mucin exocytosis. Am Rev Respir Dis 1991, 144 S33-S37

42. Grootjans J, Hundscheid IH, Lenaerts K, Boonen B, Renes IB, Verheyen FK, Dejong CH, von Meyenfeldt MF, Beets GL, Buurman WA: Ischaemia-induced mucus barrier loss and bacterial penetration are rapidly counteracted by increased goblet cell secretory activity in human and rat colon. Gut 2013, 62:250-258

43. Levine SJ, Larivee $\mathrm{P}$, Logun C, Angus CW, Ognibene FP, Shelhamer JH: Tumor necrosis factor-alpha induces mucin hypersecretion and MUC-2 gene expression by human airway epithelial cells. Am J Respir Cell Mol Biol 1995, 12:196-204

44. Rodriguez-Fuentes GB, Cedillo-Rivera R, Fonseca-Linan R, Arguello-Garcia R, Munoz O, Ortega-Pierres G, Yepez-Mulia L: Giardia duodenalis: analysis of secreted proteases upon trophozoiteepithelial cell interaction in vitro. Mem Inst Oswaldo Cruz 2006, 101:693-696

45. Beatty JK, Akierman SV, Motta JP, Muise S, Workentine ML, Harrison JJ, Bhargava A, Beck PL, Rioux KP, McKnight GW, Wallace JL, Buret AG: Giardia duodenalis induces dysbiosis of human intestinal microbiota biofilms. Int J Parasitol 2017, 47: $311-326$

46. Ndao M, Beaulieu C, Black WC, Isabel E, Vasquez-Camargo F, Nath-Chowdhury M, Masse F, Mellon C, Methot N, NicollGriffith DA: Reversible cysteine protease inhibitors show promise for a Chagas disease cure. Antimicrob Agents Chemother 2014, 58: $1167-1178$

47. Doyle PS, Zhou YM, Engel JC, McKerrow JH: A cysteine protease inhibitor cures Chagas' disease in an immunodeficient-mouse model of infection. Antimicrob Agents Chemother 2007, 51:3932-3939

48. Marco M, Coteron JM: Falcipain inhibition as a promising antimalarial target. Curr Top Med Chem 2012, 12:408-444 
49. Das P, Alam MN, Paik D, Karmakar K, De T, Chakraborti T: Protease inhibitors in potential drug development for Leishmaniasis. Indian J Biochem Biophys 2013, 50:363-376

50. Beatty JK, Bhargava A, Buret AG: Post-infectious irritable bowel syndrome: mechanistic insights into chronic disturbances following enteric infection. World J Gastroenterol 2014, 20:3976-3985

51. Kanazawa M, Fukudo S: Relationship between infectious gastroenteritis and irritable bowel syndrome. Clin J Gastroenterol 2014, 7: 14-18

52. Khan WI, Blennerhasset P, Ma C, Matthaei KI, Collins SM: Stat6 dependent goblet cell hyperplasia during intestinal nematode infection. Parasite Immunol 2001, 23:39-42

53. Gouyer V, Dubuquoy L, Robbe-Masselot C, Neut C, Singer E, Plet S, Geboes K, Desreumaux P, Gottrand F, Desseyn JL: Delivery of a mucin domain enriched in cysteine residues strengthens the intestinal mucous barrier. Sci Rep 2015, 5:9577

54. Radhakrishnan P, Halagowder D, Devaraj SN: Altered expression of MUC2 and MUC5AC in response to Shigella infection, an in vivo study. Biochim Biophys Acta 2007, 1770:884-889

55. Gerbaba TK, Gupta P, Rioux K, Hansen D, Buret AG: Giardia duodenalis-induced alterations of commensal bacteria kill Caenorhabditis elegans: a new model to study microbial-microbial interactions in the gut. Am J Physiol Gastrointest Liver Physiol 2015, 308:G550-G561

56. Maia-Brigagao C, Morgado-Diaz JA, De Souza W: Giardia disrupts the arrangement of tight, adherens and desmosomal junction proteins of intestinal cells. Parasitol Int 2012, 61:280-287

57. Scott KG, Meddings JB, Kirk DR, Lees-Miller SP, Buret AG: Intestinal infection with Giardia spp. reduces epithelial barrier function in a myosin light chain kinase-dependent fashion. Gastroenterology 2002, 123:1179-1190

58. Teoh DA, Kamieniecki D, Pang G, Buret AG: Giardia lamblia rearranges $\mathrm{F}$-actin and alpha-actinin in human colonic and duodenal monolayers and reduces transepithelial electrical resistance. J Parasitol 2000, 86:800-806

59. Bergstrom KS, Kissoon-Singh V, Gibson DL, Ma C, Montero M, Sham HP, Ryz N, Huang T, Velcich A, Finlay BB, Chadee K, Vallance BA: Muc2 protects against lethal infectious colitis by disassociating pathogenic and commensal bacteria from the colonic mucosa. PLoS Pathog 2010, 6:e1000902

60. Buret AG, Amat CB, Manko A, Beatty JK, Halliez MCM, Bhargava A, Motta J-P, Cotton JA: Giardia duodenalis: new research developments in pathophysiology, pathogenesis, and virulence factors. Curr Trop Med Rep 2015, 2:110-118 